\title{
Construction Safety Audit and Analysis - A Conceptual Approach on Needy Implementation for the Metropolitan City-Chennai, India
}

\author{
A. Anandraj,, S. Vijayabaskaran \\ Assistant Professor, Saranathan College of Engineering, Trichy-madurai road Panjappur, Venkateswara Nagar, Edamalaipatti Pudur, Tamil Nadu \\ 620012, India
}

DOI: $10.36348 / \mathrm{sb} .2020 . v 06 \mathrm{i} 08.001$

| Received: 30.07 .2020 | Accepted: 06.08.2020 | Published: 30.08.2020

*Corresponding author: A. Anandraj

\section{Abstract}

Construction safety audit is a prescribed course of action for assessing accident prospective and safety performance in the prerequisite of new construction schemes, the development and rehabilitation of existing structures and in maintenance of building structures. The main objective of this study is the identification of accident prone areas on the project site from First Investigation Report (FIR), to study the effect on development of statistical connection between accident rates and various factors that causing accidents. The scope of the study is to reduce accidents on construction site and its surroundings, reducing severity of accidents so as the necessity for costly remedial work is reduced. The aspect of safety is taken on low priority basis throughout the execution of construction projects in India. The area selected for the study is Chennai, a metropolitan and capital of Tamil Nadu. Tamil Nadu lies in the southernmost part of the Indian Peninsula and one of the 28 states of India. The accident analysis is prepared from five years statistics. Various types of labours and staffs are interviewed accordingly in order to get the clear depiction of site accidents with the personal measure which is the ultimate goal of this research paper.

Keywords: Construction Safety, Safety Audit, Construction Site Accidents, Safety in India.

Copyright @ 2020: This is an open-access article distributed under the terms of the Creative Commons Attribution license which permits unrestricted use, distribution, and reproduction in any medium for non-commercial use (NonCommercial, or CC-BY-NC) provided the original author and source are credited.

\section{INTRODUCTION \\ BACKGROUND}

The Construction Safety Audit (CSA) process started in 1970 "s in the UK, moved to USA and New Zealand in 1980s, and was introduced in Australia in mid -1980s [1-4]. A means of know-how of audit has been gained since 1990 in the UK. Construction Safety Audit has been engaged up in major way in Australia and New Zealand where guidelines have been published and in Denmark where construction safety audits are mandatory to all construction projects. Now, World Bank has announced it mandatory that all World Bank aided construction projects would be audited from the personnel safety point of view [5-10].

\section{Construction Safety in India}

In India, at present there is no formal or prescribed requirement for construction safety audits to be undertaken. However, India has also started realizing the importance of construction safety audits. Being temporary phase in nature, the construction sectors are the most vulnerable phase of industries or businesses involving large temporary worker force and involving maximum number of accidents. The National Safety Council (national and unit levels), has been conducting training programmes, information dissemination, producing awareness material and organizing campaigns for the construction industries for over a decade [11, 12].

\section{OBJECTIVES OF THE STUDY}

Each catastrophe calls for systematic study in a scientific manner and comprehensive investigation of the accident spot. This type of investigation will assist to recognize some of the causative factors accountable for accidents and to give relative significance. The results of the study could be employed beneficially to take up pre-emptive measures to reduce the accidents.

The objectives of the present study are,

- Identification of accident prone areas on the Chennai Area from First Investigation Report.

- To study the effect of site conditions and working culture conditions on the area. 
- Development of statistical relationship between accident rates and various factors causing accidents

\section{Scope of the study}

- The accidents on construction site can be reduced.

- The severity of accidents can be reduced.

- The need for costly remedial work is reduced.

\section{CONSTRUCTION INCIDENTS AND LACK OF TRAININGS OVERVIEW \\ Construction accidents are exclusively} dependent on the improper training of labours. Research had shown that in many sites no skilled development plan exist in Chennai. Negligence of safety standards will absolutely result in the form of disasters and loss of valued human life. According to a study, most common types of accidents that occur to specific job, investigation has shown that carpenters have more finger injuries compared to masons. During execution of construction work labours faced different types of accidental issues including falls, scaffolding, electrical related matters, operating equipments or machineries, welding and explosion accidents etc. All of these are equally hazardous and deadly, and each of these can be avoided through effective safety trainings and measures $[13,14]$.

\section{Implications for the metropolitan of Chennai and dependent areas}

Chennai is one of the capital economical hubs of India, for getting employment, education and medical facilities peoples migrated all around the India to Chennai. Many of these migrants getting employment related to construction work. Construction firms getting profit of this unemployment fraction and sign up cheap unskilled labour on a daily basis wages to execute the job, this might source to the amplified number of site accidents. Many contactors do have the safety policy, on document but in practice there is no check and balance of safety constriction. Unemployed labour involving themselves in menace during execution of construction projects and gain knowledge from their own mistakes. Also construction equipments manufacturers have a responsibility to design, devise and maintain safe products for use at the work site. This responsibility includes preventing the use of defective or unreasonably dangerous products, which include: scaffolding, power tools, cranes, woodworking tools, ladders, winches, trucks, tractors, bulldozers, forklifts etc [15]. When a construction site accident occurs, the owners, architects, insurance companies and manufacturers of equipment can be held responsible for inadequate safety provisions $[16,17]$.

\section{CONSTRUCTION SAFETY ANALYSIS SURVEY Analytical Facts}

A questionnaire is a series of questions asked to persons to acquire statistically constructive information about a specified topic. When appropriately constructed and sensibly administered, questionnaires become a imperative instrument by which statements can be prepared about specific groups or people or entire populations. Questionnaires are commonly used in quantitative marketing research and social research. They are a valuable method of collecting a wide range of information from a large number of individuals [18].

Various oral records and few written records are collected from construction each site located in and around Chennai. It has seen that there are no proper written records of any information regarding constructional safety. Hence it has been advised that orderly formatted safety records must be available in the establishments and firms without delay and at reasonable time it should be examined by the experienced safety personnel. These records must be maintained for a period of not less than five years following the end of the calendar year to which they relate. Such records must contain at least the following facts [19]:

- About the Employer.

- About the injured or ill employee.

- About the accident or exposure to occupational illness.

- About the remedy or diagnosis to the employee.

- About the prevention steps taken over the accident.

In order to overcome the above mentioned problems a brief questionnaire was planned by taking the help from different questions. In the similar fashion, numbers of targeted sites are visited in Chennai with the stringent observation that labours are having associated with the number of problems and these problems are directly engaged with the inadequate construction safety process. This questionnaire was given to various hierarchy staffs and specifically to site labourers who was larger in number as compared to total construction personnel. The designed model questionnaire is specified in Table-1 [20]. 
Table-1: Designed Questionnaire

\begin{tabular}{|c|c|c|}
\hline $\begin{array}{l}\text { Question } \\
\text { Code }\end{array}$ & Questions & Answer \\
\hline A & $\begin{array}{l}\text { Where is your work place? } \\
\text { 1) Office 2) Construction site 3) Site/office 4) Others }\end{array}$ & \\
\hline B & $\begin{array}{l}\text { How many hours you work daily? } \\
\text { 1) } 8 \text { Hrs 2) } 10 \text { hrs 3) Part time 4) Shift work }\end{array}$ & \\
\hline $\bar{C}$ & $\begin{array}{l}\text { Did you ever attend safety courses, if yes state where did you receive training? } \\
\text { 1) Labour Dept. 2) OSHA 3) In-house 4) None }\end{array}$ & \\
\hline $\mathrm{D}$ & $\begin{array}{l}\text { High accidents rates on construction site are due to } \\
\text { 1) Lack of legislation 2) Lack of safety knowledge 3) High staff turnover 4) Careless } \\
\text { worker attitudes }\end{array}$ & \\
\hline $\mathrm{E}$ & $\begin{array}{l}\text { Is the income is adequate to sustain your dependants? } \\
\begin{array}{l}\text { 1) Yes 2) No }\end{array}\end{array}$ & \\
\hline$F$ & $\begin{array}{l}\text { How many times you are injured during construction work? } \\
\text { 1) Nil 2) Less than } 3 \text { times } 3 \text { ) More than } 3 \text { times 4) Severe injury }\end{array}$ & \\
\hline $\bar{G}$ & $\begin{array}{l}\text { Have you got any compensation or aid against your injury from the owner } \\
\text { 1) Yes 2) No }\end{array}$ & \\
\hline $\mathrm{H}$ & $\begin{array}{l}\text { Are you provided of proper personnel protective equipment? } \\
\text { 1) Yes 2) No }\end{array}$ & \\
\hline I & $\begin{array}{l}\text { What will be your response if there is a serious accident happened in your site? } \\
\text { 1) Stop work until the risk of accident cleared 2) continue work \& study the cause } 3 \text { ) } \\
\text { review the construction procedures w.r.t. safety 4) no action to take }\end{array}$ & \\
\hline $\mathrm{J}$ & $\begin{array}{l}\text { Which types of accident happen on site very often? } \\
\text { 1) Fall of person from height 2) Collapse of demolition 3) Failure of scaffolding 4) } \\
\text { Fall of material hoist }\end{array}$ & \\
\hline
\end{tabular}

Each one of the above framed questions is assigned with a separate code for the effective formulation in graphical representation.

Then the data collected are depicted as follows. As per the question code B, C, D, E, F, G, H and I more than $85 \%$ answers are leading to the prevailing unsafe construction safety procedures. It is quite obvious from the analytical facts that formulation of effective construction safety audit with predefined rules for the employer/labour locality is compulsory and it is only possible with the introduction safety culture in the building environment. The graphical representation of the construction safety analysis survey is given in Figure-1.

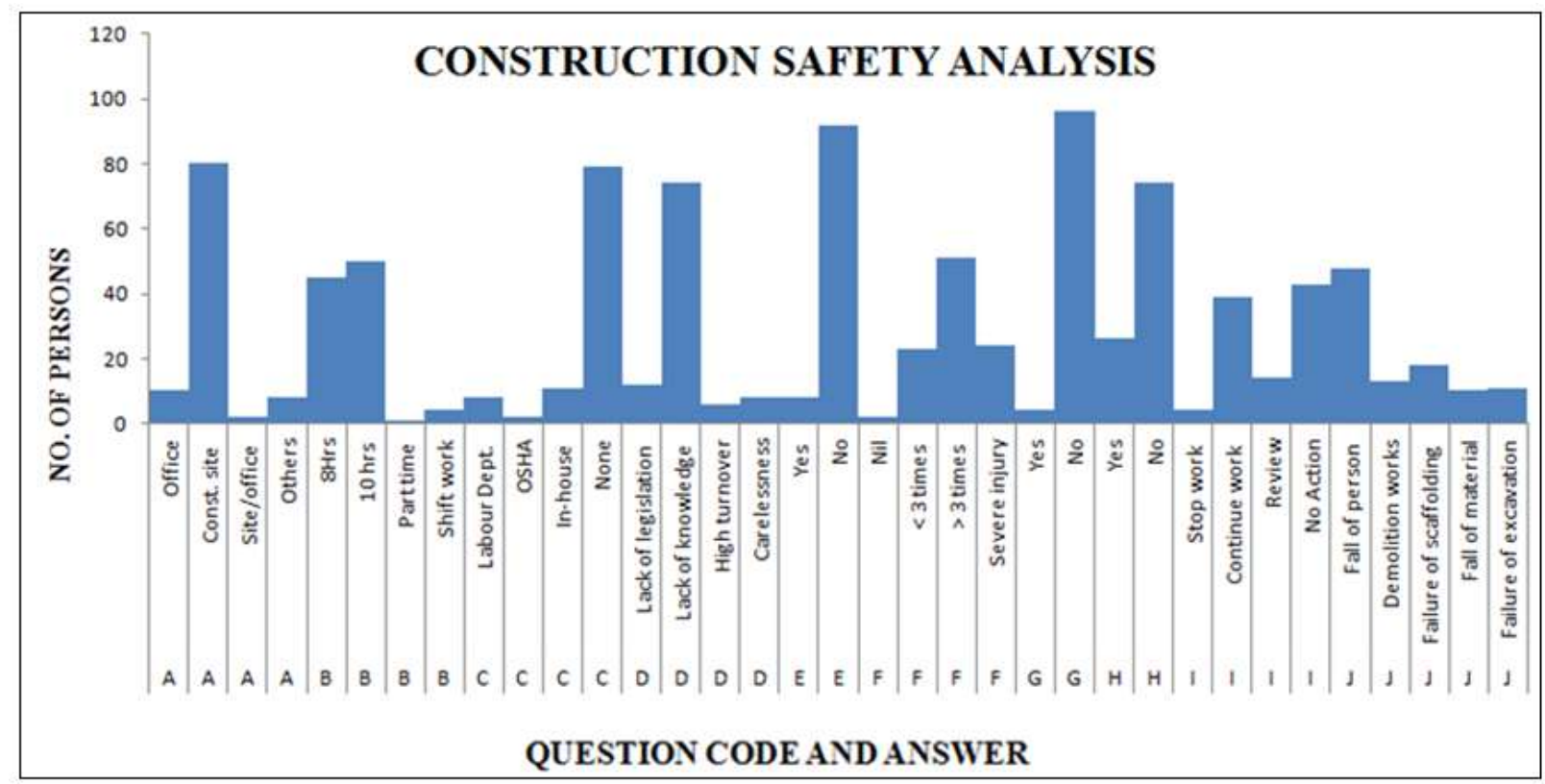

Fig-1: Construction Safety Analysis survey 


\section{ROLE OF DIFFERENT ORGANIZATION IN CSA General}

CSA is based on the principle of an independent review. The procedure reveals that three parties will be concerned in this process - Client, Designer/Contractor and auditor.

\section{Role of Designer/Contractor}

Designer/Contractor is accountable for planning/executing the project. Designer bears the liability for ensuring that a construction safety audit is conducted and that the indispensable measures are approved on the basis of the auditor's recommendations and/or the client's decisions. The designer/contractor is also answerable for ensuring that the audit input information is unambiguously defined and that all state of affairs are described in an easily understood manner.

\section{Role of Client}

Client is one who allots the project to the designer/contractor and owns the project. It is the task of the client to adjudicate or arbitrate in cases where the designer and auditor disagree. The role of the client thus to:

- Select an appropriate audit team.

- Provide all the applicable and necessary documents.

- Felicitate a commencement meeting with auditor and designer /contractor.

\section{Role of Auditor}

Auditor's responsibility is to carefully review the presented project material in it's entirely, in the light best construction safety expertise and from the viewpoints of all relevant labours and workers. Auditor also indicates all circumstances that cause misgivings concerning site safety. Persons designated as construction safety auditors shall have experience of construction project site accident analysis. Auditors must be familiar with construction planning, designing, executing and must undertake to keep their expertise up to date. Auditors should work within the terms of reference. They should comment only on the safety implications of schemes and provide constructive recommendations as to how any potential difficulties can be resolved.

\section{TEAM SELECTION}

For large or significant projects, it is likely to have at least four members in the audit team, but not more than eight members. For small projects, two team members will be sufficient. One of the team members should be nominated as CSA manager. The one essential ingredient in CSA team is Construction safety engineering experience. It is also better to include localexperienced people.

\section{AUDIT ORGANIZATION \\ Audit Options}

Practically three options are there for conducting a Construction Safety Audit:

- Audit by specialist auditors.

- Audit by those within the original design team or by any other designers.

- Audit by local safety personnel.

\section{Stages in CSA}

There are five stages at which a construction safety audit can be conducted, regardless of the size and nature of a project. They are:

- The feasibility stage.

- The draft design stage.

- The detailed design stage.

- The pre-execution stage

- The execution stage and

- The audit of an existing building.

The earlier a construction site is audited within the design and development process the better. If an appropriate concept or treatment (i.e. one with intrinsic safety inconvenience in the particular context) is preferred at the feasibility stage, it is very difficult and, often impossible to remove safety problems at later design stages or once the client is using it, early auditing can also lead to early exclusion of problems and, consequently, minimization of exhausted design time at later stages.

\section{PRESENT INVESTIGATION General}

The objective of the present study is to establish an experimental relationship between accident rate and some factors influencing accidents. In order to build up such relationship, it is indispensable to gather the accident data and details about the factors affecting the accident rate, such as lack of safety training, protection equipments etc. The accident statistics for five years have been collected and used for the investigation. Surveys were conducted to collect the details like nature of work/site, workforce volume, prolonged working hours and etc. at selected locations.

\section{Location}

The whole Chennai metropolitan and its surrounding areas were selected for analysis. The Chennai Metropolitan Area is the fourth largest metropolitan area in India and the 30th in the globe in terms of population (as of 2010). The CMA composed of the metropolitan city of Chennai (Madras) and its suburbs.

Chennai city (not to be confused with Chennai district) currently covers an area of 426 sq. kilometres and includes adjoining sections of Tiruvallur and Kanchipuram districts along with the 176 sq kilometres of the Chennai District. Prior to the expansion in 
September 2011, the city of Chennai (administered by the Chennai Corporation) fell entirely within Chennai District.

The CMA falls in three Districts of the Tamil Nadu State viz. Chennai District, part of Thiruvallur district, and part of Kanchipuram district. The extent of the Chennai District (enclosed in Chennai Municipal Corporation area) is $176 \mathrm{~km}^{2}$ and comprises 55 revenue villages in five Taluks [viz. (i) Fort-Tondiarpet Taluk, (ii) Perambur-Purasawalkam Taluk, (iii) Egmore-
Nungambakkam Taluk, (iv) Mambalam-Guindy Taluk and (v) Mylapore-Triplicane Taluk. In Tiruvallur District out of total district area of $3427 \mathrm{~km}^{2}, 637 \mathrm{~km}^{2}$. in Ambattur, Thiruvallur, Ponneri and Poonamallee taluks fall in CMA.

In Kanchipuram District out of $4433 \mathrm{~km}^{2}$, $376 \mathrm{~km}^{2}$ in Tambaram, Sriperumbudur and Chengalpattu Taluks fall in the Metropolitan area. The present study is limited to analysis of construction sector accidents during the years 2011 to 2016.

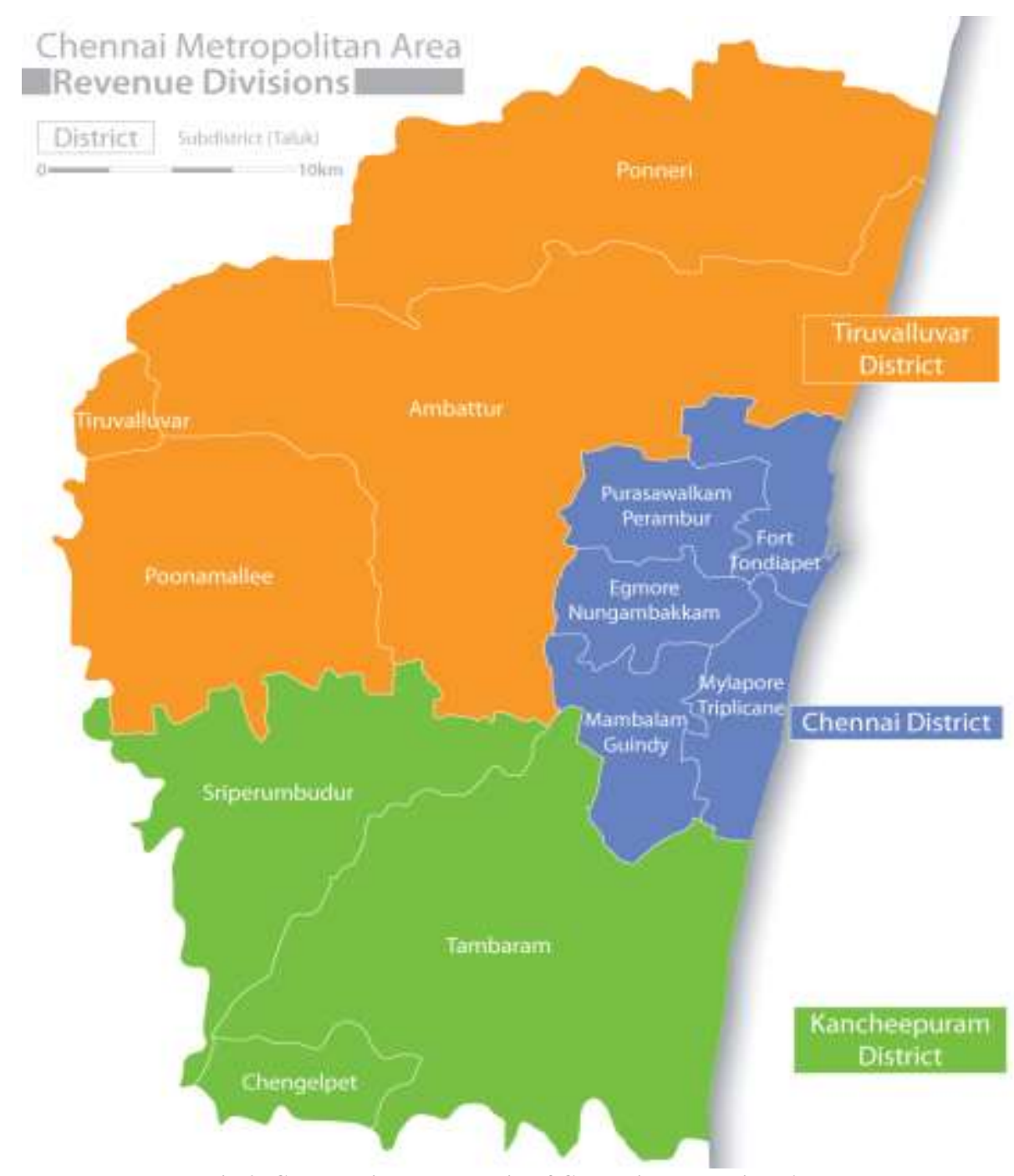

Fig-2: Geographical Map details of Chennai Metropolitan Area

\section{Collection of Accident Data}

The accident particulars pertaining to the study stretch was collected from the respective police stations. The study stretch falls under the administration of Chennai Metropolitan Police Station limit. The Chennai Metropolitan Police, a division of the Tamil Nadu Police, is the law enforcement agency for the city of Chennai in India and the surrounding area. The city police force is headed by a Commissioner of Police and the administrative control vests with the Tamil Nadu Home ministry. There are thirty six sub-divisions of the Greater Chennai Police, and 122 police stations. The accident data form has been prepared to collect the necessary information such as date, time, location, whether the accident was fatal, injured and equipment damage.

Accident data related to past five years was collected for analysis purpose. Since this analysis is done at macro level some of the data like Name of the companies, firms, contractors are not disclosed in order to maintain the good will of the respective sectors. But 
all the arrived findings, results and recommendations are conveyed to the respective firms as free consultancy. According to the professional business ethics it's not only criticizing or error spotting of the managements that will result in the upliftment from present prevailing conditions but also providing technically constructive ideas and recommendations which alone show the way to attain preferable or healthy working environment.

\section{ANALYSIS OF DATA \\ Accident Analysis}

The data concerning the construction site accidents in and around Chennai metropolitan area have been collected for a period of five years, i.e. 2014 to 2019 from the Chennai Metropolitan Police Station. The date, time, approximate place, types of injuries involved etc., are entered in the First Information Report (F.I.R) and details are recorded in case diaries. In order to evaluate accident data, it was found that the particulars were not recorded in standard format and police FIR lacked the important engineering aspects like Nature of Accidents, Type of location, etc. Therefore, micro level investigation is not feasible. The unskilled labours are most affected by accidents in the construction site. The workers safety is very low. Accidents which occurred during the study period, i.e. 2014 - 2019, are arranged Year-wise, Month-wise and Hour-wise. It is observed that more number of accidents has occurred in the year 2016.

To understand the causes of accidents, it is important to examine Area-wise trends of the accidents, which will help to identify the accident prone stretches of the construction network. Area-wise distribution of accidents is shown in Table-2. It was observed that most of the accidents are happening in the developing regions of Chennai Metropolitan Area where more number of construction projects, both small scale and large scale projects are under progress. Graphical representation of Area-wise accidents is accessible in Figure-3.

Table-2: Area wise distribution of accidents during 2014-2019

\begin{tabular}{|l|l|l|l|l|l|l|}
\hline Area & Fatal & Injured & Seriously Injured & Equipment Damage & Total & Percentage (\%) \\
\hline Ponneri & 3 & 16 & 3 & 2 & 24 & 7.23 \\
\hline Ambattur & 4 & 28 & 6 & 4 & 42 & 12.65 \\
\hline Poonamallee & 4 & 21 & 3 & 1 & 29 & 8.73 \\
\hline Perambur & 4 & 18 & 4 & 1 & 27 & 8.13 \\
\hline Egmore & 5 & 23 & 4 & 2 & 34 & 10.24 \\
\hline Fort & 4 & 21 & 3 & 2 & 30 & 9.04 \\
\hline Mylapore & 5 & 19 & 5 & 1 & 30 & 9.04 \\
\hline Guindy & 6 & 27 & 6 & 3 & 42 & 12.65 \\
\hline Sriperumbudur & 2 & 12 & 2 & 3 & 19 & 5.72 \\
\hline Tambaram & 6 & 14 & 4 & 1 & 25 & 7.53 \\
\hline Chengelpet & 3 & 20 & 5 & 2 & 30 & 9.04 \\
\hline & & & & Total & 332 & \\
\hline
\end{tabular}

The factors that are largely contributing in the degrading issues of construction safety are lack of proper safety education and vocational training, un-safe site conditions, un-safe method of practices, underprovided enforcement of safety, lack of safety equipments, non-usage of provided equipments, deprived attitude towards work and working environment. The effectiveness of any construction safety audit depends upon the active participation and co-operation of the construction managers, safety personnel, supervisors and employees with the coordination of their efforts with the audit authority who are engaged in safety auditing.

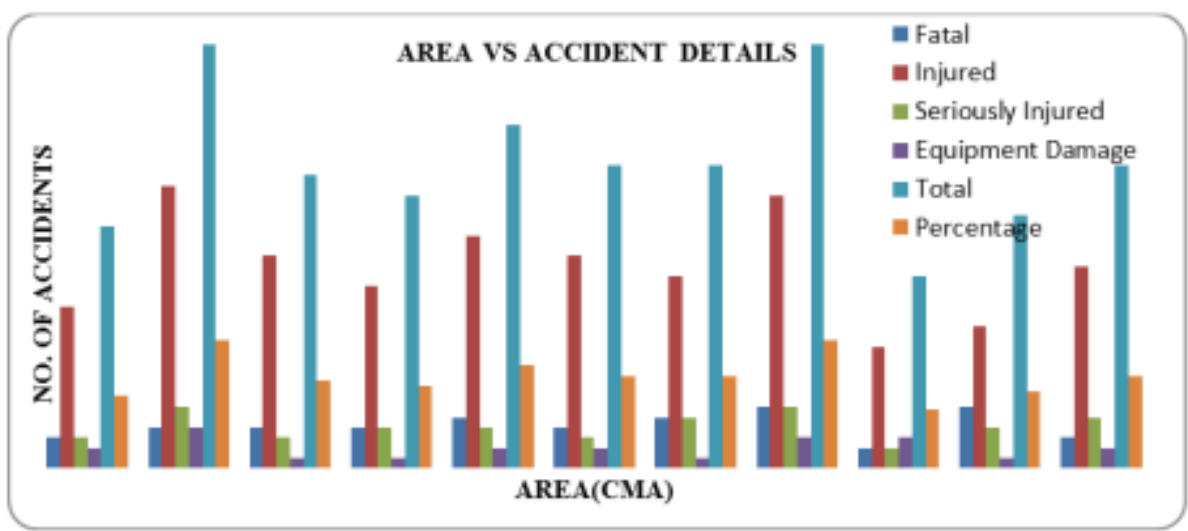

Fig-3: Area Vs Accident Details during 2014-2019 
In this analysis safety regarding the unskilled workers who are large in numbers among the total population of construction workers is very low on these areas. Moreover areas like Ambattur and Guindy acts as major accident prone zone since more number of construction projects including residential flats, flyover's and metro rail constructions are in rigorous progress in this area. The rate of unskilled labours affected by accident is shown in Table-3 and graphically represented in Figure-4.

Table-3: Un-Skilled labour affected by accidents during 2014-2019

\begin{tabular}{|l|l|}
\hline DESCRIPTION & NO. OF PERSONS \\
\hline Total No. Of Accidents & 332 \\
\hline Un-Skilled Labours & 197 \\
\hline Others & 135 \\
\hline PERCENTAGE (Un-Skilled) (\%) & 59.34 \\
\hline PERCENTAGE (OTHERS) (\%) & 40.66 \\
\hline
\end{tabular}

The basic procedures while dealing with unskilled workforce that are to be carried out during a construction safety audit are:

- Recognition - Keeping up a system which results in prompt detection with timely rectification of unsafe construction practices and working conditions that are imposed on un-skilled workforce.

- Education - Establish and conduct safety training program to stimulate on safety related issues like attending safety meetings, use of personnel protective equipments, etc to unskilled workforce.
- Investigation - All incidents and claims should be investigated to determine the causes and to take reasonable corrective actions. Local safety engineers should be engaged here to communicate with un-skilled workforce.

- Planning - Planning all works to minimize personnel injury, property damage and loss of time.

- Regulation - Comply with the central and state laws, prescribed standards, regulations and requirements.

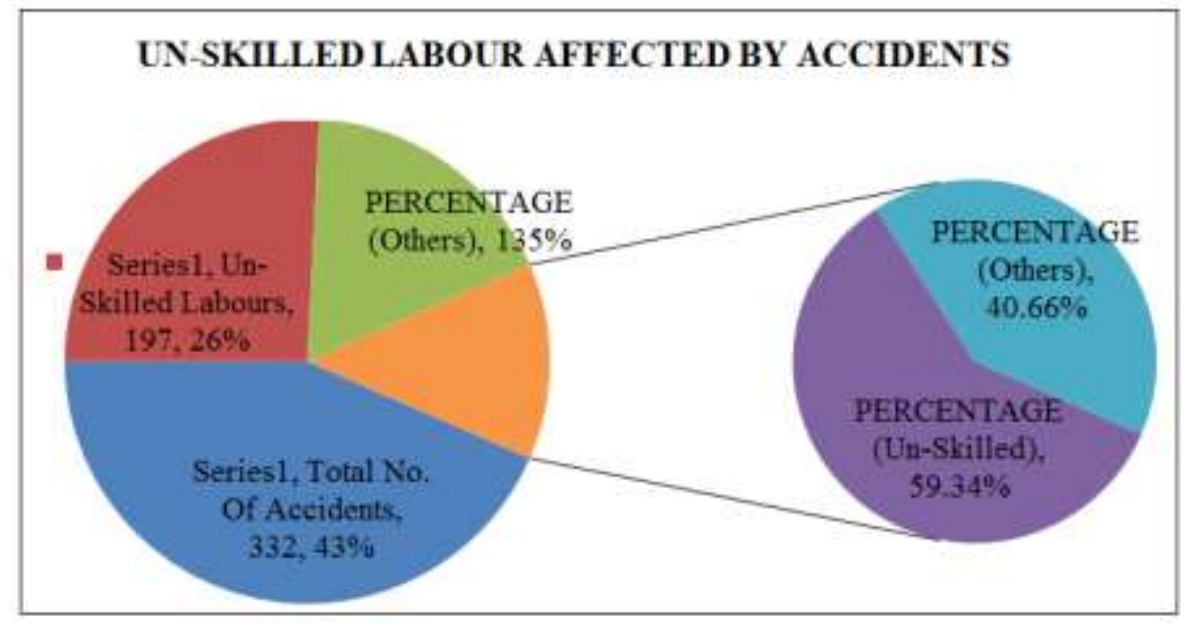

Fig-4: Un-skilled labour affected by accidents details during 2014-2019

The percentage of un-skilled labours is about $59.34 \%$ and others are about 40.66. Hence it clearly depicts that more un-skilled labours are the victims of accidents during the chosen year intervals.

\section{CONCLUSION \\ General}

The study area of Chennai Metropolitan Area is accident prone due to multiplicity of causative factors. The analysis of accident data collected from the FIRs from 2014 to 2019 and field surveys conducted has yielded the following conclusions.

\section{Accident Statistics}

- More number of accidents due to safety issues has occurred during 2016.

- No specific trend is observed with month wise distribution, and the accidents have occurred all through the year because of various combinations of safety disorders.

- Majority of minor accidents has occurred during failure of scaffoldings, falling while excavations due to lack of knowledge and carelessness hence it is difficult to explain the particular trend. 
- Majority of severe injuries has occurred during fall of person from heights and demolition works.

- Analysing area wise accident occurrence has shown that the areas like Ambattur, Guindy, Egmore and Chengelpet are highly prone to higher accident rates.

\section{Construction Safety Audit}

The analysis has indicated that the most severe accident prone locations are Ambattur and Guindy. These areas needs an overall improvement, re-framing of safety policies on workers, etc., and needs "Earlier" and "Later" studies to be conducted for cost-effective and economic evaluation. To enhance the features of the construction safety sector of Chennai Metropolitan Area following ideas should be considered as the recommended measures in this construction safety audit:

- Construction sector is the active industry among all the revenue generation sectors. The pragmatic justifications counting the standards and objectives toward safety, productivity, etc should be well defined.

- The respective paper is linked with the formulation of construction safety audit, in this connection the active policies should be revised as per the prevailing conditions and sensibly implemented.

- Institutional and document level might be severe by showing the ideas of all concerned stakeholders, this could only be achievable by the organization of effectual seminars/ forums in which the owning bodies should take impart to express their views.

- Construction Safety must be given the preceding significance.

- Well-built Coordination and relationship should be developed among the lower, middle and superior authorities of any construction assignment regarding safety issues.

- Government sector should be down to business in order to take the decisions for the evasion of construction safety. This may be inhibited by the enhanced and effectual check balance system.

- Public-personal joint venture programs should be promoted sequentially to generate the sense of balance between efficient productivity, construction safety and well being.

- The operational hours should be assigned and allotted for each type of labours including daily wages and on weekly and monthly basis.

- Contractors and Consultants association should be well developed and made susceptible.

- Appropriate safety trainings should be introduced for each category of workforce working in the construction sector in order to closing the gap between theoretical and practical applications.

- It should be made mandatory for the workforce to be implicated in these types of trainings all through the whole career.

- Safety or personnel protective equipments/ accessories should be provided in order to endure in critical situations.

- Child manual labour should be dispirited by highlighting the precise age limits for working.

- Not only it should be just provided, the labours should be given the relevant trainings to use the specific type of equipments.

- Set of laws, regulations, policies and by-laws should be well and predefined in the separate sections of prevailing applied safety policies.

- For every construction activity in Chennai, the labour wages should be re-considered and revised; this will make certain the less contribution of labours in additional work which eventually decrease the site accidents.

- Data acquirement of systematic facts and figures is the vital device for the retained system. The partners should take attention to build up these types of report clusters.

- At least a single construction safety engineer should be allotted for any construction project and his function should be made cautious by straight correspondence from each single venture holder.

\section{ACKNOWLEDGEMENTS}

The author highly appreciates the contribution of Chennai Metropolitan Police for their kind behaviour in issue of records for research purpose. The hearty appreciation also extended to various company authorities and staffs who actively gave their participation for this research.

\section{REFERNCES}

1. Levitt, R. E., \& Samelson, N. M. (1987). Construction safety management, McGraw-Hill, New York

2. Hinze, J., \& Wiegand, F. (1992). Role of designers in construction worker safety. Journal Constr Eng Manage. 118(4):677-684.

3. Lunch, M. F. (1995). Labor Department resurrects its attempt to bring A/Es under OSHA standards. Build Des Constr. 36(9):31.

4. Gambatese, J. A., Hinze, J., \& Haas, C. T. (1997). Tool to design for construction worker safety. Journal Archit Eng. 3(1):32-41.

5. Lunch, M. F. (1997). Differing verdicts reached on design firm liability for safety. Build Des Constr. 38(8):21.

6. Gambatese, J. A. (1998). Liability in designing for construction worker safety. Journal Archit Eng. 4(3):107-112. 
7. Hinze, J., Pederson, C., \& Fredley, J. (1998). Identifying root causes of construction injuries. Journal Const Eng Manage. 124(1):67-71.

8. Bigelow P. L., Greenstein S. L., Keefe T. J., \& Gilkey D. P. (1998). Development of an on-site, behavior-based safety audit for the residential construction industry. Journal Work. 11-20(10).

9. Smith, T. W., III. (1998). Site safety: Rights, risks, and responsibilities. Civil Eng. 68(5):55.

10. Korman, R., Kohn, D., \& Daniels, S. H. (1999). Undeserved attention. Designers say OSHA is unfairly expanding safety responsibility without clear legal basis. Engineering News Record, 21(June), 28-32.

11. Sawacha, E., Naoum, S., \& Fong, D. (1999). Factors affecting safety performance on construction sites. International journal of project management, 17(5), 309-315.

12. Court finds for $\mathrm{CH} 2 \mathrm{M}$ Hill, $\mathrm{A} / \mathrm{Es}$ in site safety case. (1999). Eng Times. 21(10):1.

13. Abdelhamid, T. S., \& Everett, J. G. (2000). Identifying root causes of construction accidents. Journal of construction engineering and management, 126(1), 52-60.
14. Gambatese, J. A. (2000). Safety in a Designer's Hands. Civil Engineering, 70(6), 56-59.

15. Loulakis, M. C., \& Santiago, S. J. (2000). Do OSHA construction standards apply to designers?. Civil Engineering, 70(1), 72.

16. Wilson, J. M., \& Koehn, E. E. (2000). Safety management: problems encountered and recommended solutions. Journal of construction engineering and management, 126(1), 77-79.

17. Suraji, A., Duff, A. R., \& Peckitt, S. J. (2001). Development of causal model of construction accident causation. Journal of construction engineering and management, 127(4), 337-344.

18. Toole, T. M. (2002). Comparison of site safety policies of construction industry trade groups. Practice Periodical on Structural Design and Construction, 7(2), 90-95.

19. Toole, T. M., \& Gambatese, J. A. (2002). Primer on federal OSHA standards. Pract Period Struct Des Constr. 7(2):56-60.

20. Ng, S. T., Cheng, K. P., \& Skitmore, R. M. (2005). A framework for evaluating the safety performance of construction contractors. Building and environment, 40(10), 1347-1355. 